\title{
What is More Important? Physical Attractiveness Or General Cognitive Ability As Factors of Career Development
}

\author{
Valerij Dermol \\ International School for Social and Business Studies, Slovenia \\ valerij.dermol@mfdps.si
}

\begin{abstract}
Purpose: The investigate the causal and correlation relationships between physical attractiveness, general cognitive ability, career aspirations and age as predictors of career development.
\end{abstract}

Study design/methodology/approach: The collected qualitative data were analysed with SPSS statistical programme. Basic descriptive statistics were used, and linear regression analysis and correlation analysis since hypotheses related to causal and correlation relationships were tested.

Findings: The results show that physical attractiveness strongly and positively affects career development. A bit weaker but negative influence was recognised from the side of individual's age. There is no correlation found between age, cognitive abilities and physical attractiveness.

Originality/value: This research is preliminary research that represents a basis for further investigation of the field and introduces a more complex model that may serve as a base for further research.

Keywords: physical attractiveness, general cognitive ability, career aspirations, age, career development

\section{Introduction}

Several studies on the influence of physical attractiveness on various aspects of human activity, including work performance and career, can be detected in the literature. However, fewer studies focus on the causal relationships between physical attractiveness and work context, especially those dealing with career impacts. Moreover, most of the studies in the literature are not designed to include the aspect of cognitive intelligence or general cognitive ability examining possible interactions between cognitive intelligence and physical attractiveness and their relationship with career and career development.

As we have already indicated, the research problem we intend to address in our paper is based on the conventional dilemma of most influencing an individual's professional career - whether intelligence or physical attractiveness or beauty.

The paper aims to conceptualise and operationalise the variables under the investigation, design a model presenting the context of professional career development and test it on a sample of female respondents. The study is intended to be a base for further research.

The paper is organised into three parts. In the Introduction, the key concepts are shortly introduced, such as physical attractiveness, general cognitive ability or cognitive intelligence, and the concept of career and career development. The relationships between these concepts are outlined as well, resulting in the construction of a research model; however, more in-depth literature is still needed. In the second part of the paper, the research methods used in the study are explained together with statistical analysis, including basic descriptive analysis, as well as testing the research model with the use of linear regression analysis. In the third part of the paper, a short discussion with key findings and suggestions for further research are included. 


\section{The conceptualisation of the research model}

\section{Physical attractiveness as a factor of career performance}

Physical attractiveness is the degree to which a person's physical characteristics are considered aesthetically pleasing or beautiful. It is often associated with sexual attraction or desirability. The concept of physical attractiveness includes universal notions common to all cultures. People often attribute other positive qualities, such as intelligence and honesty, to physically attractive people (Definitions, 2021). Science explores physical attractiveness primarily in terms of its impact on social interaction, establishing romantic relationships and friendships, offering help, socio-cultural influences on children, links to ageing standards, student assessment, court convictions, voter preferences, and professionally related situations by perceiving physically attractive individuals with better qualifications for a particular job and better work results, that attractive individuals obtain better recommendations for employment, that they can advance their careers more easily, have higher salaries, etc. (Davison \& McCabe, 2011; Ellis et al., 2019; Frederick et al., 2012; Furnham et al., 2012).

Research shows that physical attractiveness is more important than other, less noticeable personal characteristics of individuals. For example, Weeden and Sabini (2005) find that externally attractive life partners are already seemingly healthier, age-appropriate, reproducible, and as such perceived as suitable for a partner role. Physical attractiveness seems to be important primarily because people associate it with other, favourable characteristics that we expect from others. Because of this, as Fugère (2017) and Fugère et al. (2017) sums up, attractive people are happier and generally have better life experiences than unattractive people experience on average. At first glance, the physical attraction seems to be related to an individual's self-image, that individual's experience by others, and an individual's performance in a social context. As Fugère (2017) and Fugère et al. (2017) point out, such conclusions apply to both sexes and different cultural environments. Nevertheless, a slightly closer look at physical attractiveness distinguishes between levels of attraction. It finds that high levels of attraction are mostly not the most desirable among people who choose partners and that comparability of partners' physical attractiveness is vital for a long-term, successful relationship (Castro et al., 2014).

Talamas et al. (2016), e.g. in their research, examine the impact of physical attractiveness on academic performance, which also significantly affects a student's subsequent performance in the labour market. The regression analysis concludes that academic performance statistically predicts only diligence, and correlation analysis does not confirm the correlation between physical attractiveness and actual academic performance. However, it confirms a strong positive correlation between physical attractiveness and perceived intelligence, as well as perceived academic performance. So it seems that the more physically attractive a student is, the more his environment perceives him to be diligent, intelligent, and academically successful (see also Homan, 2016).

\section{General cognitive ability as a factor of career performance}

The cognitive ability could be closely related to the concept of intelligence. We define intelligence from several aspects. It can be defined as a set of higher-level cognitive abilities such as, e.g. abstract reasoning, mental representation, problem-solving and decision making. It can also be defined as the ability to learn, emotional knowledge and creativity; it can also be perceived as the ability to successfully achieve and meet the requirements that come to the individual from his environment. An IQ test based on the Binet-Simon scale from the early 19 th century, for example, is used today to determine an individual's intelligence. Although IQ tests are generally reliable and valid, they have their drawbacks as they do not consider cultural 
specificities. In addition to the concept of intelligence, the concept of general cognitive ability (Batty, 2013) may also be in the focus of intelligence-related research. It can be defined as the ability to cope with cognitive complexity, i.e., several mental operations with information, such as recognising similarities, recognising inconsistencies, reasoning and summarising, and perceiving new concepts. General mental abilities could be defined as "intelligence in action."

Research supports the idea that general mental abilities and thus intelligence are a good indicator of career success. Some authors (e.g., Schmidt, \& Hunter, 1998, 2000, 2004) even believe that depending on the type of work and how performance is measured, general mental abilities explain even between $30 \%$ and $70 \%$ of changes in an individual's work performance. With the work performance of individuals, in this case, we primarily aim to assess performance measurement throughout the performance appraisals in the assessment of tasks, planned performance appraisals are done by supervisors and achievement regarding the position in the professional hierarchy. However, some researchers doubt that cognitive ability is essential for individuals' work performance, as "intuition can tell that personality and other non-cognitive traits are more important" (Caplan, 2013; Hunter \& Schmidt, 1970, 1996). Analyses of causeeffect relationships between various work performance factors suggest that general cognitive ability or cognitive intelligence has the most decisive influence on acquiring professional knowledge. Namely, people with a higher level of this ability acquire more of this kind of knowledge; besides, they acquire it faster (Schmidt \& Hunter, 1998, 2000, 2004). Of course, the amount of expertise required in more complex jobs is more significant, which may mean that the cognitive intelligence factor in such positions is more important than in less demanding ones.

\section{Career - career development and career aspirations}

A career can be defined as a pattern of work experience that directs a person's life (Greenhouse et al., 1995). It is, in fact, a job for which one is qualified and in which one is enabled to advance during one's working life. The advancement can be reflected in greater responsibility and higher earnings (Career, n.d.). Therefore, a career is not limited only to work context but also to the entire life path. Svetlik and Zupan (2009) explain that career and its development are one of the critical areas of dealing with people at work. As a result, practically no companies do not pay much attention to the employees' careers and their development. Namely, activities in this field can bring added value and measurable effects at the level of human capital and the entire organisation's operation.

Toit (2013) note that the most frequently listed personal predictors of career success are, for example, demographic predictors such as gender, language groups, marital status and age. There might also be some work-related predictors such as hours worked, work experience, willingness to transfer, occupational tenure, international experience, and accomplishment rating. It seems that job tenure and level of education are robust predictors of subjective career success, which may also be an indicator of another predictor, t. i. subjective career aspirations.

Based on their literature review, Gray and O'Brien (2007) summarise that women's career choices were as either having homemaking or a career orientation decades ago. However, in recent years, research about women's career choices focuses on variables such as degree of career versus family orientation, traditional versus non-traditional career choice, and prestigious versus non-prestigious occupational selection. In their own empirical research, Gray and O'Brien, 2007 also emphasise the importance of leadership and achievement aspirations and educational aspirations, accounted for substantial variance in the career aspiration among primarily white women. 


\section{Research method}

\section{Research model}

The purpose of this research is to assess the extent to which an individual's career development is influenced by his general cognitive ability or cognitive intelligence, physical attractiveness and career aspirations. The connection will also be explored in terms of age as one of the factors influencing career development.

The choice of the research methods is based on the logic of the research model presented in Fig.1. Since the research is based on quantitative data and a model compiled based on literature and studies already offering some clearly defined theoretical relationships, we are going to test the following research hypotheses with the use of appropriate statistical tests:

H1: Physical attractiveness has a positive effect on career development.

H2: General cognitive ability has a positive effect on career development.

H3: Career preferences have a positive effect on career development.

H4: Age has a negative effect on career development.

H5: Physical attractiveness and general cognitive ability are negatively correlated.

H6: Career aspirations are positively related to physical attractiveness.

H7: Career aspirations are positively related to general cognitive ability.

H8: Age is negatively related to career aspirations.

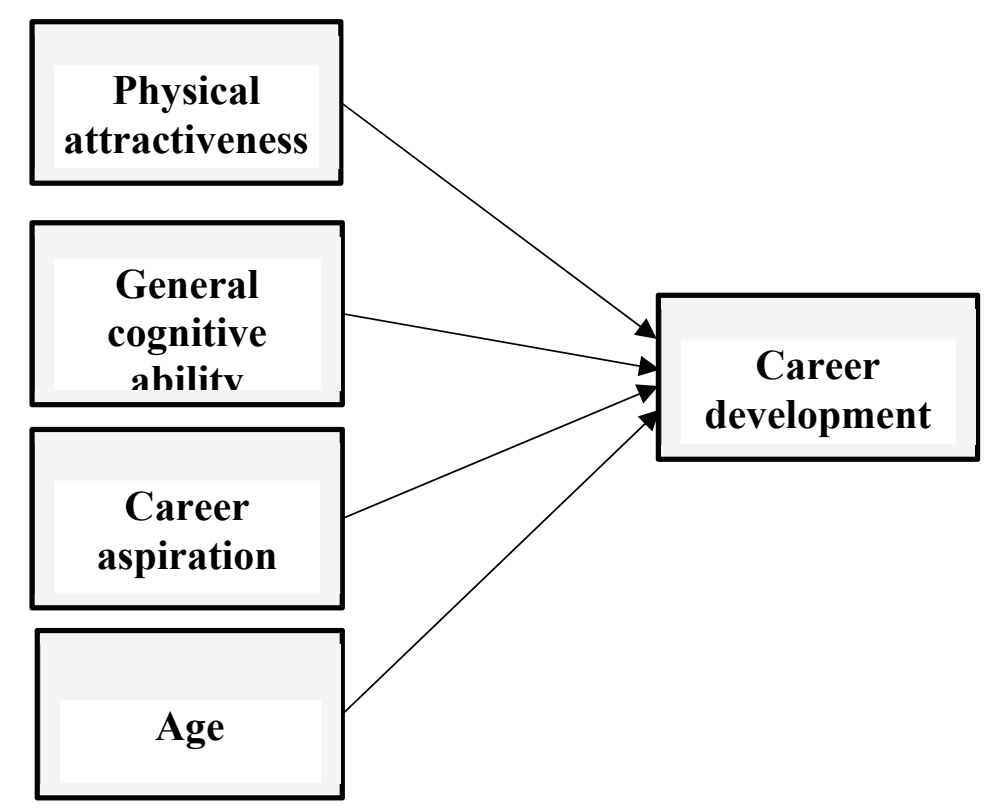

Figure 1: The research model

\section{Collecting the data and the sample}

Data needed for the statistical analysis was collected by using a questionnaire, which in addition to demographic data (gender, age and job complexity), contained 3 measurement scales requiring answers from the stock of values from 1 to 5 or from 1 to 10 or 1 to 5 (Likert scale). The measurement scales enabled the operationalisation of physical attractiveness, general 
cognitive ability, career aspirations and career development. Already validated questionnaires identified in the literature (Ferreira et al., 2013; Gray \& O'Brien, 2007; Swami et al., 2007; Toit, 2013) were used. As already mentioned, the questions will be collected as part of a literature review. The questionnaire was distributed among the respondents with an online survey tool 1KA. The measurement scales are presented in Table 1.

The measurement scales were first checked individual by using Cronbach alpha and afterwards also by exploratory factor analysis. In the latter case, we entered into the analysis all the dependent measurement indicators simultaneously. All the indicators that belonged to more factors would mean too high interdependencies between the factors were removed from the measurement scales. The remaining indicators of individual measurement scales are presented in Table 1. In the next step of the analysis, we calculated the mean values of the measurement indicators and, this way, assigned the values to the independent as well as dependent variables of the investigated model (i.e., career aspiration, physical attractiveness, general cognitive ability, career development).

The sample comprised 48 units. Since the study represents a pilot study of the phenomena and enabled us to implement the envisaged statistical methods, we believe that the results represent a valid and valuable starting point for further research. In the sample, only females were represented, among them $50 \%$ of age between 35 and 44 years, $19 \%$ between 25 and 34 years of age and the rest between 45 and 64 years. $81 \%$ of respondents were employed, $15 \%$ selfemployed, and $4 \%$ unemployed. Regarding education, $58 \%$ of respondents achieved bachelorlevel education, $19 \%$ master or doctoral degree, and 15\% high-school education.

\section{Analysis and results}

\section{Descriptive statistics}

As part of the statistical analysis, which was used to obtain answers to confirm or reject research hypotheses, we performed descriptive statistics (i.e., calculations of arithmetic mean values, standard deviations) and selected methods of inferential statistics to test the research model (i.e., linear regression analysis), and relationships between the physical attractiveness and general cognitive ability.

Table 1: Measurement scales and descriptive statistics

\begin{tabular}{|l|l|l|l|}
\hline Career aspiration scale & $\begin{array}{l}\text { Mean } \\
\text { value }\end{array}$ & $\begin{array}{l}\text { Standard } \\
\text { deviation }\end{array}$ \\
\hline CA1 & I hope to become a leader in my career field. & 3.67 & 1.1 \\
\hline CA2 & $\begin{array}{l}\text { When I am established in my career, I would like to manage other } \\
\text { employees. }\end{array}$ & 3.38 & 1.07 \\
\hline CA3 & When I am established in my career, I would like to train others. & 4.05 & 0.92 \\
\hline CA4 & I hope to move up through any organisation or business I work in. & 3.81 & 1.08 \\
\hline CA5 & $\begin{array}{l}\text { Once I finish the basic level of education needed for a particular job, I } \\
\text { see no need to continue in school.* }\end{array}$ & 4.14 & 1.28 \\
\hline CA6 & I plan on developing as an expert in my career field. & 4.00 & 1.10 \\
\hline CA7 & Attaining leadership status in my career is not that important to me.* & 4.33 & 0.80 \\
\hline & & & \\
\hline Physical attractiveness scale & & \\
\hline $\begin{array}{l}\text { When I physically compare myself with my colleagues, friends or } \\
\text { other known girls, I feel }\end{array}$ & & \\
\hline PA1 & Inferior-superior & 6.29 & 1.40 \\
\hline PA2 & Undesirable-more desirable & 6.75 & 1.75 \\
\hline PA3 & Unconfident-more confident & 6.71 & 2.05 \\
\hline PA4 & Ugly-beautiful & 6.38 & 2.34 \\
\hline PA5 & Left out—-accepted & 7.54 & 2.55 \\
\hline PA6 & Devalued- valued & 7.58 & 2.30 \\
\hline
\end{tabular}




\begin{tabular}{|c|c|c|c|}
\hline PA7 & Ignored-looked up & 7.29 & 2.48 \\
\hline PA8 & Less popular-more popular & 6.50 & 1.75 \\
\hline PA9 & Despised-envied & 6.50 & 2.17 \\
\hline \multicolumn{4}{|c|}{ General cognitive ability } \\
\hline GCA1 & I follow the story in the book I am reading & 3.85 & 0.81 \\
\hline GCA2 & I understand spoken guidelines or instructions & 4.40 & 0.50 \\
\hline GCA3 & I find my car in the parking lot & 4.25 & 0.55 \\
\hline GCA4 & I find my way back to the mall or another place & 4.35 & 0.81 \\
\hline GCA5 & I find my way in a famous neighbourhood & 4.60 & 0.50 \\
\hline GCA6 & I orient myself in a well-known store & 4.65 & 0.49 \\
\hline GCA7 & I orient myself in a house I have visited many times & 4.42 & 0.77 \\
\hline GCA8 & I anticipate weather changes and plan accordingly & 3.40 & 1.05 \\
\hline GCA9 & I plan my schedule in advance for scheduled events & 4.05 & 0.69 \\
\hline GCA10 & I think ahead & 4.40 & 0.50 \\
\hline GCA11 & I manage personal finances without mistakes & 3.85 & 0.75 \\
\hline GCA12 & I keep my financial records organised & 3.80 & 0.83 \\
\hline GCA13 & I use organised strategies to manage my medication schedule & 3.15 & 1.35 \\
\hline \multicolumn{4}{|c|}{ Career development } \\
\hline CD1 & I receive positive feedback from all over about my performance & 4.35 & 0.59 \\
\hline CD2 & I am dedicated to my work & 4.43 & 0.51 \\
\hline CD3 & I'm in a position to mostly do jobs that I like & 4.19 & 0.87 \\
\hline CD4 & My co-workers respect me & 4.37 & 0.60 \\
\hline CD5 & I get good performance ratings & 4.62 & 0.50 \\
\hline CD6 & My co-workers accept me & 4.52 & 0.51 \\
\hline CD7 & I have the trust of my superior & 4.35 & 0.75 \\
\hline CD8 & I get good job ratings & 4.60 & 0.50 \\
\hline CD9 & I am happy with my private life & 4.26 & 0.65 \\
\hline CD10 & I enjoy my extracurricular activities & 4.42 & 0.51 \\
\hline CD11 & I am happy with my life in general & 4.16 & 0.69 \\
\hline CD12 & I am dedicated to my work & 4.37 & 0.68 \\
\hline CD13 & I am happy with the progress I have made so far & 4.20 & 0.77 \\
\hline CD14 & I achieve my career goals within the time frame I have set for myself & 3.85 & 0.93 \\
\hline CD15 & I will achieve all my professional goals & 3.90 & 0.72 \\
\hline CD16 & I am in a job that offers opportunities for advancement & 3.85 & 0.81 \\
\hline CD17 & I get fair pay compared to my peers & 3.65 & 0.99 \\
\hline CD18 & I receive a high income compared to my peers & 2.90 & 1.25 \\
\hline CD19 & I earn as much as I find my work worthwhile & 3.10 & 1.41 \\
\hline
\end{tabular}

Note: * calculated from reversed scale

As we can see from Table 1, the respondents showed quite strong career aspirations. They highly evaluated their aspiration to attain leadership positions $(\mathrm{m}=4.33)$, continue with further training after finishing basic schooling $(\mathrm{m}=4.14)$, and also take on the role of a trainer of their co-workers $(\mathrm{m}=4.05)$. They also showed strong intentions to become an expert in their career fields $(\mathrm{m}=4.00)$. On the other hand, the aspiration to manage other employees after completing their professional careers shows to be relatively weaker $(\mathrm{m}=3.38)$.

On a general level, the self-image of physical attractiveness seems quite pleasing among the respondents (all items are higher than 6.28 on the scale from 1 to 10 ). It appears that the respondents feel to be valued, accepted and looked up to. It should be stressed that the findings are based on the subjective comparison between a respondent and her friends, colleagues or familiar people in her social context.

General cognitive ability is also quite high evaluated by the respondents. As shown in Table 1, all the items have a value above 3 which somehow indicates a medium value. The highest abilities self-graded by the respondents are space orientation in a well-known store $(\mathrm{m}=4.65)$, 
in their neighbourhood $(\mathrm{m}=4.60)$, or finding back from a location $(\mathrm{m}=4.35)$ and finding a car $(\mathrm{m}=4.25)$ as well as communication-related cognitive abilities such as understanding spoken words $(\mathrm{m}=4.40)$, and planning skills like thinking ahead $(\mathrm{m}=4.40)$ and scheduling in advance $(\mathrm{m}=4.05)$.

When analysing the dependent variable, i.e. career development, we can also conclude that the average values of the measurement variables are pretty high. The respondents especially emphasise their work performance, i.e., good performance ratings $(\mathrm{m}=4.62)$, good job ratings $(\mathrm{m}=4.60)$, positive feedback from all over about job performance (4.35); good relationships established at work, i.e., acceptance by the co-workers (4.52) as well as their respect (4.37); individuals' dedication to their work (4.43), as well as opportunities to learn, for example as a part of extracurricular activities (4.42). The lowest assigned value belongs to receiving a high income compared to peers $(\mathrm{m}=2.90)$.

\section{Inference statistics}

Multiple regression analysis was used to test if respondents' career aspiration, assessments of physical attractiveness, and general cognitive ability and the respondents' age significantly predict their ratings of career development. The results of the linear regression analysis indicate that the four predictors explain $53.3 \%$ of the variance $\left(\mathrm{R}^{2}=0.73, \mathrm{~F}(4,15)=4.28, \mathrm{p}<0.05\right)$, which is a rather good result of the analysis. It was found that career development is statistically significantly predicted by physical attractiveness $(\beta=0.50, \mathrm{p}<0.05)$ and age of the respondents $(\beta=-0.44, p<0.05)$. On the other hand, general cognitive ability and career aspiration do not seem to be statistically significant predictors of career development. We can somehow conclude that self-perception of physical attractiveness relatively strongly predicts the career development of an individual. However, it can be relatively strongly influenced by the individual's age. The older an individual is, the lesser is the self-perceived probability of career development.

We also tested the correlation between the two predictors of career development - physical attractiveness and general cognitive ability. The relationship between the two variables showed a non-significant correlation of $r=-0.8, p>0.05$, which means that we cannot assume an interrelation between the perception of physical attractiveness and perception of general cognitive ability.

Also, correlation analysis was done to test relationships between career aspirations, general cognitive ability and an individual's age. All the relationships were found to be negative; however, statistically non-significant.

\section{Discussion and conclusions}

As we conclude in Table 2, physical attractiveness, at least its perception, has a strong and positive influence on career development. It seems that women who consider themselves as valued, accepted and looked up may have better career achievements such as self-perceived work performance, quality social relationships established at work or realisation of opportunities to learn.

Another finding of this research relates to the age of an individual. Statistical analysis somehow confirms general beliefs saying that an increase in individuals' age decreases career development possibilities. Interestingly, the analysis does not show any correlation between age and career development. One would expect a negative correlation. 
Surprisingly, the analysis does not show any relationship between career aspirations and career development, neither any correlation between career aspirations and other variables such as physical attractiveness, general cognitive ability or age.

Our research findings might even confirm general beliefs about career development and job promotion. Namely, individuals perceived as younger and more physically attractive have better chances for advancement at work, regardless of their career aspirations and general cognitive abilities.

Table 2: Testing the hypotheses

\begin{tabular}{|l|l|l|}
\hline H1 & Physical attractiveness has a positive effect on career development. & Confirmed \\
\hline H2 & General cognitive ability has a positive effect on career development. & Rejected \\
\hline H3 & Career preferences have a positive effect on career development. & Rejected \\
\hline H4 & Age has a negative effect on career development. & Confirmed \\
\hline H5 & Physical attractiveness and general mental ability are negatively correlated. & Rejected \\
\hline H6 & Career aspiration is positively related to physical attractiveness. & Rejected \\
\hline H7 & Career aspiration is positively related to general cognitive ability. & Rejected \\
\hline H8 & Age is negatively related to career aspirations. & Rejected \\
\hline
\end{tabular}

The research has, of course, some limitations. First, it is a relatively small sample that may bias the findings and the restriction of gender since only female respondents participated in the research. Further, the questionnaire might also be a limitation since the data is based on strictly subjective ratings of physical attractiveness and other variables. The model might be upgraded based on further literature review. For further investigation, we also suggest upgrading the model by introducing additional relevant latent variables and connections between them.

\section{References}

Batty, R. (2013, May 1). Intelligence matters more than you think for career success. 80,000 Hours. https://80000hours.org/2013/05/intelligence-matters-more-than-you-think-for-career-success/

Career. (n.d.). Retrieved from https://dictionary.cambridge.org/dictionary/english/career

Caplan, B. (2013, April 9). The Effect of Intelligence on Job Performance is Intuitive. Econlib. https://www.econlib.org/archives/2013/04/the_effect_of_i.html

Castro, F., Hattori, W., Yamamoto, M., \& Lopes, F. (2014). Social Comparisons on Self-Perception and Mate Preferences: The Self and the Others. Psychology, 5, DOI: 10.4236/psych.2014.57080.

Davison, T. E., \& McCabe, M. P. (2011). Physical Attractiveness. V Brown, B. B., in Prinstein, M. J. (ed.), Encyclopaedia of Adolescence. San Diego: Academic Press.

Definitions. (2021). What does physical attractiveness mean? Retrieved from https://www.definitions.net/definition/physical+attractiveness

Ellis, L., Farrington, D. P., \& Hoskin, A. W. (2019). Handbook of Crime Correlates. San Diego: Academic Press.

Ferreira, C., Pinto-Gouveia, J., \& Duarte, C. (2013). Physical appearance as a measure of social ranking: The role of a new scale to understand the relationship between weight and dieting. Clinical Psychology and Psychotherapy, 20, 55-66.

Frederick, D. A., Reynolds, T. A., Fales, M. R., \& Garcia, J. R. (2012). Physical Attractiveness: Dating, Mating, and Social Interaction. V Cash, T. (ed.), Encyclopaedia of Body Image and Human Appearance. Oxford: Academic Press.

Fugère, M. A., Chabot, C., Doucette, K., \& Cousins, A. J. (2017). The Importance of Physical Attractiveness to the Mate Choices of Women and Their Mothers. Evolutionary Psychological Science, 3(3), 243-252.

Fugère, A. M. (2017). Why Physical Attraction Matters, and When It Might Not. Psychology Today. Retrieved March 13, 2021, from https://www.psychologytoday.com/blog/dating-and-mating/201701/why-physicalattraction-matters-and-when-it-might-not 
Furnham, A., Kosari, A., \& Swami, V. (2012). Estimates of Self, Parental and Partner Multiple Intelligences in Iran: A replication and extension. Iran J Psychiatry, 7(2):66-73

Gray, P. G., \& O'Brien, K. M. (2007). Advancing the Assessment of Women's Career Choices: The Career Aspiration Scale. Journal of Career Assessment, 15(3), 317-337.

Greenhouse, J. H., Callanan, G. A., \& Kaplan, E. (1995). The role of goal setting in career management. International Journal of Career Management, 7(5).

Homan, M. (2016). Vpliv telesne podobe na karierno uspešnost posameznika (bachelor thesis). Ljubljana: Univerza v Ljubljani, Fakulteta za družbene vede.

Hunter, J., \& Schmidt, F. (1970). Intelligence and job performance: Economic and Social Implications. Psychology, Public Policy, and Law, 2, 447-472.

Hunter, J. E., \& Schmidt, F. L. (1996). Intelligence and Job Performance: Economic and Social Implications. Psychology. Public Policy and Law, 2, 447-472.

Schmidt, F., \& Hunter, J. (1998). The Validity and Utility of Selection Methods in Personnel Psychology. Psychological Bulletin, 124, 262-274.

Schmidt, F. L., \& Hunter, J. E. (2000). Select on intelligence. Handbook of principles of organisational behavior, 3(14).

Schmidt, F. L., \& Hunter, J. E. (2004). General mental ability in the world of work: occupational attainment and job performance. Journal of personality and social psychology, 86(1), 162.

Svetlik, I., \& Zupan, N. (2009). Menedžment človeških virov. Ljubljana: Fakulteta za družbene vede.

Swami, V., Furnham, A., Georgiades, C., \& Pang, L. (2007). Evaluating self and partner physical attractiveness. Body image, 4, 97-101.

Talamas, S. N., Mavor, K. I., \& Perrett, D. I. (2016). Blinded by Beauty: Attractiveness Bias and Accurate Perceptions of Academic Performance. PLoS ONE, 11(2). Retrieved from https://doi.org/10.1371/journal.pone.0148284

Toit, A. M. (2013). The psychometric evaluation and predictors for two subjective career success instruments (Mini dissertation). Potchefstroom Campus: North-West University.

Weeden, J., \& Sabini, J. (2005). Physical Attractiveness and Health in Western Societies: A Review. Psychological Bulletin, 131, 635-653. 